\title{
BIOENERGETICS OF THE CAVE CRICKET, HADENOECUS SUBTERRANEUS
}

\author{
Eugene H. Studier, Kathleen H. Lavoie, William D. Wares II and Julie A.-M. LinN* \\ Department of Biology, University of Michigan-Flint, Flint, MI 48503, USA
}

(Received 25 October 1985)

\begin{abstract}
In late spring, cave crickets in Mammoth Cave National Park were investigated in order that their bioenergetics might be elucidated.

2. A predictive relation between crop-empty live weight and hind femur length independent of sex was found.

3. Long-term weight loss patterns were 1.55 and $1.19 \mathrm{mg} / \mathrm{hr}$ for females and males, respectively, suggesting feeding intervals of 11.5 and 9.9 days.

4. Calorific assimilation efficiencies were found to be $80.4 \%$ for females and $82.5 \%$ for males.

5. The estimated maximal metabolic rates were half that expected for insects of similar mass.

6. The mixed waste calorific levels were found to be exceptionally low.
\end{abstract}

\section{INTRODUCTION}

With the exception of irregular climatic phenomena, such as high winds and floods (Hawes, 1939), cavedwelling trogloxenes, such as some bats and cave crickets, appear to provide the major and certainly the most dependable source of fixed carbon input to temperate cave ecosystems (Barr, 1967; Barr and Kuehne, 1971; Richards, 1971; Harris, 1973). Trogloxenes are animals which spend the bulk of their time inside caves, but must leave the cave to feed (Barr, 1968). Many of the caves found in Mammoth Cave National Park (MCNP), Kentucky, are populated by cave crickets (Hadenoecus subterraneous) which, in the absence of large colonies of bats, provide the major food input to these caves. Cave cricket eggs, waste and carcasses have been implicated as extremely important sources of food for obligate cave-dwelling troglobites (Poulson and Kane, 1981; Kane et al., 1975; Peck, 1976). Campbell (1980) completed an extensive study of several Australian cave-dwelling crickets. The literature available on the biology of $H$. subterraneus includes a monograph on their taxonomy and distribution (Hubbell and Norton, 1978), foraging activities and feeding habits (Levy, 1976) and a brief report on temporal patterns of emergence from caves and foraging (Leja and Poulson, 1984). Estimates of the quantitative importance of the crickets to energy flow in cave ecosystems are hindered by the lack of reports concerning the energy economics of individual cave crickets.

\section{MATERIALS AND METHODS}

Studies were conducted during the last week of April, and the first week of May, 1985, in Floyd Collins Crystal Cave and White Cave in MCNP, KY. To establish a potential relationship between hind femur length and carcass weight, attempts were made to collect crickets as they exited and

*Present address: Department of Health Behavior/ Education, School of Public Health, University of Michigan, Ann Arbor, MI, 48104 USA. returned to the cave. Collections were also made from resident roosting crickets. The date, time and location of collection, as well as the gender of crickets were noted. All crickets were killed within $\mathbf{3 0}$ min of capture by exposure to chloroform fumes. Within an hour of capture, whole crickets were weighed, dissected, and any crop contents as well as enlarged reproductive tracts were weighed. Hind femur length (FL) was measured to the nearest $0.1 \mathrm{~mm}$ with a vernier caliper. Crop-free (CF) carcasses, crop contents and reproductive tracts were dried at $55^{\circ} \mathrm{C}$ in an oven and reweighed. All weighings were made to the nearest $0.1 \mathrm{mg}$ using a mechanical analytical balance (Christian Becker, Style AB-3, Clifton, NJ).

A long-term weight-loss study was begun at $0300 \mathrm{hr}$ local time on 29 April 1985 (designated time $=0300 \mathrm{hr}$ ). Thirteen (eight female and five male) large (FL $>20.0 \mathrm{~mm}$ ) crickets with full crops were collected just inside the entrance to Floyd Collins Crystal Cave. These crickets were weighed to the nearest $\mathrm{mg}$ with a mechanical balance (Ohaus Centogram balance, Union, $\mathrm{NJ}$ ) and placed in quart jars (Ball Canning Jars). The jars were sealed with plastic screen cloth held in position with canning rings. A piece of plastic screen cloth inside the jar provided secure footing for the crickets. Jars were placed on a ledge in an area of the cave containing a large number of resident crickets. Crickets were reweighed at $1600 \mathrm{hr}$ on 29 April and at approx. $24 \mathrm{hr}$ intervals thereafter, until the experiment was terminated at $1000 \mathrm{hr}$ on 4 May (designated as $t=130.0 \mathrm{hr}$ ). The temperature and relative humidity were recorded frequently throughout the study period (certified hygrometer and temperature indicator, Model HTAB-176, Abbeon Cal, Inc., Santa Barbara, CA). Upon termination of the experiment, crickets were killed and processed as described in the previous paragraph. All wastes produced by these caged crickets were carefully collected, dried and weighed.

Crop contents, reproductive tracts, carcasses and combined wastes from caged crickets were burned in a Parr oxygen bomb calorimeter (Moline, IL) to determine energy content. Samples of mixed cricket wastes, which had accumulated over a period of years on a sheet of plastic placed under a cricket roost in the cave, had their energy content determined using the fore-mentioned calorimeter.

\section{RESULTS}

The relation of crop-free live weight (CFLW) to hind femur length (FL) in $H$. subterraneus is highly 


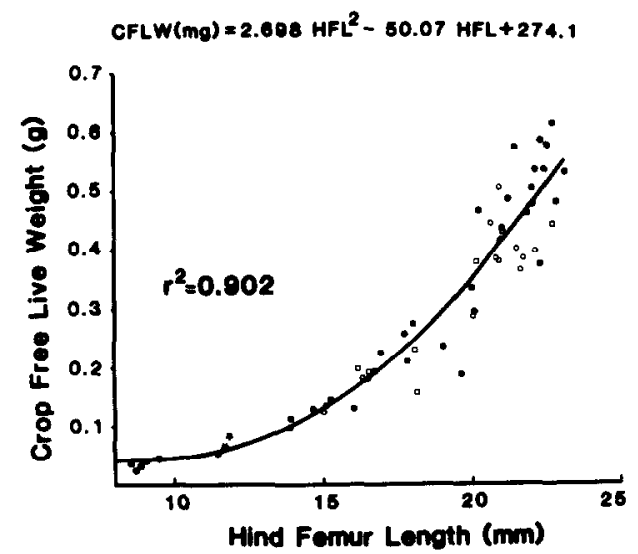

Fig. 1. The relation of crop free live weight to hind femur length in Hadenoecus subterraneus. Circles represent females and squares represent males. Stars represent unsexed individuals. Closed squares and circles are for total weight of crickets with naturally empty crops. Open circles and squares are for carcass weight with crops dissected out.

significant $(F=252.9 ; 2$ and 55 d.f.; $P<0.0001)$ as shown in Fig. 1 and expressed by the equation

$$
\begin{aligned}
& \text { CFLW }(\mathrm{mg})=
\end{aligned}
$$

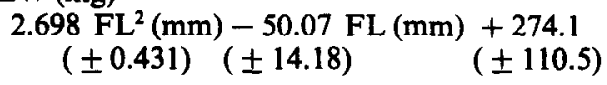

where values in parentheses are standard errors of the means. This relation has a coefficient of determination $\left(r^{2}\right)$ of 0.902 and is the same for both males and females. The relation is also unaffected whether CFLW was measured for crickets with naturally empty crops or with crop contents removed.

The long-term weight loss of caged cave crickets is shown in Fig. 2. the relation of total body weight to time for large (average $F L=21.9 \mathrm{~mm}$ ) females is highly significant $(F=112.8 ; 1$ and 54 d.f.; $\left.P<0.0001 ; r^{2}=0.676\right)$ and is expressed by

$$
\begin{aligned}
& \text { weight }(\mathrm{mg})=-1.550(\text { time }=\mathrm{hr}) \\
&( \pm 0.146)+850.2 \\
&( \pm 11.5) .
\end{aligned}
$$

Weight loss of large (average $\mathrm{FL}=21.3 \mathrm{~mm}$ ) males with time is also highly significant $(F=18.34 ; 1$ and 33 d.f.; $P=0.0001 ; r^{2}=0.357$ ) and is expressed by

$$
\begin{aligned}
& \text { weight }(\mathrm{mg})=-1.186(\text { time }=\mathrm{hr}) \\
&( \pm 0.277)+671.0 \\
&( \pm 21.8) .
\end{aligned}
$$

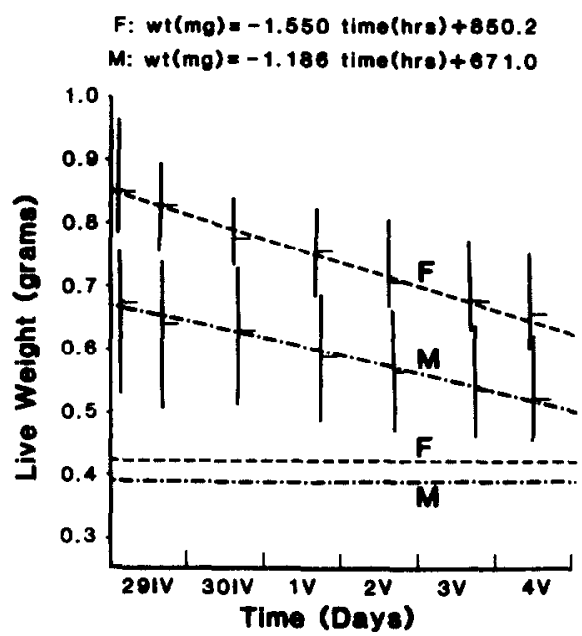

Fig. 2. Total live weight of caged large $H$. subterraneus over time beginning with crop full individuals. Symbols represent arithmetic mean and range of data. $M$-males, $F=$ females.

Also shown in Fig. 2 are the average CFLW for the male (M) and female (F) crickets studied. The elapsed time from the origin to the intercept of the CFLW line and weight-loss regressions yield an estimate of the maximal time interval between foraging exits from the cave.

Table 1 gives the calorific densities of cave cricket crop contents, carcasses, reproductive tracts and mixed wastes. It should be noted that it was necessary to pool samples from several individuals to obtain enough material for the calorimetric determinations, e.g. day 5 crop contents, fresh wastes, reproductive tracts, and carcasses of small and medium crickets. For females, dry crop content calorific density was greater by day 5 of the weight-loss studies than on day $0(t=4.79$; d.f. $=7 ; P<0.01)$. The difference in calorific density of the dry crop contents of recently fed males and females is marginally significant $(t=2.05 ;$ d.f. $=7 ; 0.01>P>0.05)$. There was no difference in the dry calorific density of fresh vs old mixed cave cricket wastes. There were also no significant differences in the calorific density of dry carcasses with reproductive tracts removed between males and females, or large, small or medium sized $\boldsymbol{H}$. subterraneus. The only significant difference in fresh

Table 1. Calorific density of cave cricket crop contents, carcasses, reproductive tracts and wastes. Values are mean \pm standard error of the mean. $F=$ female; $M=$ male; $\mathrm{B}=$ both; $\quad \mathrm{L}=$ large,$\quad \mathrm{HFL}>20.0 \mathrm{~mm} ; \quad \mathrm{ME}=$ medium,$\quad 18.0>\mathrm{HFL}>12.0 \mathrm{~mm}$;

\begin{tabular}{llcc}
\multicolumn{1}{c}{ Sample } & $N$ & $\begin{array}{c}\text { Total dry wt } \\
\text { (cal/g) }\end{array}$ & $\begin{array}{c}\text { Total wet wt } \\
\text { (cal/g) }\end{array}$ \\
\hline Crop, F, day 0, L & 5 & $3658.0 \pm 68.0$ & $1108.0 \pm 89.0$ \\
Crop, F, day 5, L & 4 & $4099.0 \pm 62.0$ & $1158.0 \pm 28.0$ \\
Crop, M, day 0, L & 4 & $4012.0 \pm 159.0$ & $1148.0 \pm 53.0$ \\
Crop, M, day 5, L & 2 & $4210.0 \pm 90.0$ & $1175.0 \pm 43.0$ \\
Fresh wastes & 2 & $2332.0 \pm 126.0$ & - \\
Old wastes & 7 & $2573.0 \pm 84.0$ & - \\
Repro. tract, F, L & 1 & 5589.0 & 3341.0 \\
Repro. tract, M, L & 1 & 3643.0 & 844.0 \\
Carcass, F. L & 6 & $4849.0 \pm 131.0$ & $1335.0 \pm 45.0$ \\
Carcass, M, L & 7 & $4565.0 \pm 171.0$ & $1232.0 \pm 59.0$ \\
Carcass, B, ME and S & 9 & $4648.0 \pm 206.0$ & $1111.0 \pm 47.0$ \\
\hline
\end{tabular}


Table 2. Energetic parameters for large ( $\mathrm{FL}>20.0 \mathrm{~mm}$ ) cave crickets, Hadenoecus subter raneus. Values shown are mean and standard error of the mean. Units are mg unless otherwise indicated; $N=8$ for females and 5 for males

\begin{tabular}{|c|c|c|c|}
\hline Parameters & Females & Males & $\mathrm{t}$ \\
\hline Wet crop wt @ $t=130 \mathrm{hr}$ & $232.4 \pm 25.7$ & $131.5+40.9$ & 2.09 \\
\hline Dry crop wt @ $t=130 \mathrm{hr}$ & $67.5 \pm 8.3$ & $36.2 \pm 12.7$ & 2.06 \\
\hline Carcass wet wt, $t=130 \mathrm{hr}$ & $422.0 \pm 11.0$ & $390.0 \pm 37.0$ & 0.83 \\
\hline Carcass dry wt, $t=130 \mathrm{hr}$ & $120.1 \pm 4.0$ & $92.7 \pm 9.4$ & $2.68+$ \\
\hline Total dry wt, $t=130 \mathrm{hr}$ & $187.5 \pm 8.0$ & $128.9 \pm 11.8$ & $4.11 \S$ \\
\hline Dry waste prod. (mg/hr) & $0.1177 \pm 0.0233^{*}$ & $0.0816 \pm 0.0157$ & 1.28 \\
\hline Wet cropwt @ $t=3 \mathrm{hr}$ & $427.8 \pm 23.4$ & $284.4 \pm 36.2$ & $3.32 \S$ \\
\hline Dry crop wt @ $t=3 \mathrm{hr}$ & $124.0 \pm 6.8$ & $79.3 \pm 10.2$ & $3.64 \S$ \\
\hline Dry crop wt used $(\mathrm{mg} / \mathrm{hr})$ & $0.4450 \pm 0.0358$ & $0.3395 \pm 0.0609$ & 1.49 \\
\hline Crop energy@t=3hr (cal) & $453.4 \pm 24.8$ & $318.1 \pm 41.0$ & $2.82 t$ \\
\hline Crop energy $t=130 \mathrm{hr}$ (cal) & $276.5 \pm 33.8$ & $152.3 \pm 53.5$ & $2.48 \dagger$ \\
\hline "Ingested" energy $(\mathrm{cal} / \mathrm{hr})$ & $1.394 \pm 0.149$ & $1.305 \pm 0.256$ & 0.30 \\
\hline Assimilated energy (cal/hr) & $1.059 \pm 0.119^{*}$ & $1.115 \pm 0.259$ & 0.20 \\
\hline \multicolumn{4}{|l|}{ Metabolic rate } \\
\hline (cal/g carcass wt per $\mathrm{hr}$ ) & $2.476 \pm 0.250^{*}$ & $2.811 \pm 0.579$ & 0.53 \\
\hline
\end{tabular}

$\mp=N=7 ; \dagger=P<0.05 ; \ddagger=P<0.02 ; \S=P<0.01$

wet weight calorific density was a higher calorific content of large female carcasses (without reproductive tracts) than in small and medium sized crickets of both sexes $(t=3.44$; d.f. $=13 ; P<0.01)$.

The various energetic parameters given in Table 2 are generated primarily from the long-term weightloss study. The estimate of metabolic rate assumes no increase in biomass during the period of observation, i.e. all assimilated energy was used for metabolism with no secondary productivity. This metabolic rate is, therefore, a maximal estimate.

\section{DISCUSSION}

The predictive quality of the relation of hind femur length to CFLW $\left(r^{2}=0.902\right)$, coupled to its usefulness for both sexes and applicability to cave crickets with food in their crops, allows quite accurate estimates of crop contents of crickets by determining hind femur length and total wet weight. Average wet crop contents of large, fed, female crickets $(427.8 \mathrm{mg}=100.4 \%$ of CFLW) at the start of the weight-loss experiment is higher than in males (284.4 $\mathrm{mg}=72.0 \%$ of CFLW), as seen in Table 2 . These female crickets bring more fixed energy $(474.0 \mathrm{cal})$ into the cave ecosystem than males $(326.5 \mathrm{cal})$ as the result of a single foraging period, assuming that all individuals have empty crops at exit. The greater level of ingested calories on the part of females would seem partially explained by their larger dry biomass $(120.1 \mathrm{mg})$ compared to males $(92.7 \mathrm{mg}$ ) as seen in Table 2 . On a weight adjusted basis, females ingest $3.95 \mathrm{cal} / \mathrm{mg}$ dry wt, which compares favorably with the $3.52 \mathrm{cal} / \mathrm{mg}$ dry wt ingested by males. Crop energy from a single foraging bout represents a remarkable 81.4 and $77.2 \%$ of $C F$ carcass energy content in females and males, respectively. The most comparable literature data are those of Woodring et al. (1979) on house crickets which consume $0.219 \mathrm{mg}$ (or $1.03 \mathrm{cal}$ ) $/ \mathrm{mg}$ dry wt per day (calculated from their data). Those values are remarkably higher than the $0.089 \mathrm{mg}$ (or $0.347 \mathrm{cal}) / \mathrm{mg}$ dry wt per day consumed by cave crickets.

Although crop contents represent considerable energy brought into the cave ecosystem, all of these calories are potentially available to troglobites only if full cave crickets die in the caves. The crop of $H$. subterraneus acts as a storage and fermentation chamber where a consistent assemblage of microbes degrade the forage (Lavoie et al., 1986). Long-term weight-loss (Fig. 2) represents, essentially, the rate of crop emptying in cave crickets, and can be used to estimate the time at which the crop will be empty and the cricket should leave the cave to feed. Using thc data from Fig. 2 and Table 2, the time gap between foraging is 11.5 days $(276 \mathrm{hr}$ ) for females and 9.9 days $(237 \mathrm{hr}$ ) for males. Published data indicate that most cave crickets do not forage nightly (Campbell, 1980). Leja and Poulson (1984) indicate significant surface foraging on only one of four consecutive nights. It has been suggested that surface activity of these cave crickets is somewhat limited by temperature and markedly influenced by relative humidity. These hygrophiles appear to forage only when epigean air is nearly water saturated. Since the night-time surface temperatures do not routinely approximate cave conditions $\left(13.5^{\circ} \mathrm{C} ; 100 \%\right.$ r.h. $)$, tolerable or desirable foraging weather is erratic, and one would expect cave crickets to forage at intervals which are more frequent than the intervals previously calculated. This interpretation leads to the conclusion that some crickets should exit caves to begin foraging before their crops are empty. Of 23 crickets collected as they emerged to feed, four $(17.4 \%)$ contained weighable crop contents. The shorter intervals between required foraging periods for males than females also suggests that a greater proportion of males should forage on any given night than females. Such a pattern is supported by our data with 15 of $23(65.2 \%)$ exiting crickets being males. While we have no numeric data on size distribution of roosting crickets, most roosting crickets seem to be large, i.e. FL $>20.0 \mathrm{~mm}$. Of the 23 exiting crickets examined, $16(69.6 \%)$ were small or medium sized (FL $<19.0 \mathrm{~mm}$ ). Leja and Poulson (1984) indicate that small $H$. subterraneus leave caves later and return earlier with full crops, indicating that if they find food, small crickets fill up quickly. Levy (1976) reported on baiting experiments which showed that small crickets were less selective in their foraging than medium or large crickets. Small crickets tended to fill up on the first food located 
Table 3. Percentage water and percentage assimilation efficiency of cave crickets, Hadenoecus subterraneus.

\begin{tabular}{lcc}
\hline \multicolumn{1}{c}{ Parameter } & Female $(N)$ & Male $(N)$ \\
\hline & Percentage water-large crickets (HFL $>20.0 \mathrm{~mm})$ \\
Crop, day 0 & $72.3(7)$ & $75.1(6)$ \\
Crop, day 5 & $71.2(8)$ & $75.0(5)$ \\
Carcass, day 0 & $72.5(6)$ & $73.1(7)$ \\
Carcass, day 5 & $71.5(8)$ & $76.2(5)$ \\
Gonads & $40.2(4)$ & $76.8(9)$ \\
& Percentage water-medium crickets $(18.0>$ HFL $>12.0 \mathrm{~mm})$ \\
Carcass, day 0 & $74.8(7)$ & $77.3(9)$ \\
& Percentage assimilation efficiency-large crickets \\
Dry matter & $73.9(7)$ & $71.9(5)$ \\
Calories & $80.4(7)$ & $82.5(5)$ \\
\hline
\end{tabular}

while larger crickets were more selective and chose food with the strongest smell, which correlated with calorific value.

While the calorific density of recently filled crops is nearly significantly different between males and females (Table 1), it seems improbable that there is a difference in calorific value of forage between sexes. Lack of a difference in wet crop calorific density between sexes suggests that the food of males simply has a higher water fraction than in females (Table 3). A similar difference in water content (Table 3) may explain the apparent difference in crop calorific density of female dry crop content calorific density with time (Day 0 versus day 5 in Table 1). The combined action of crop fermentation and probable intrinsic digestive activities markedly reduce the calorific density of the gut contents, resulting in combined wastes of very low calorific density (about $2.4 \mathrm{kcal} / \mathrm{g}$ dry wt, Table 1). A wide variety of small mammals exhibit fecal calorific densities greater than $3.5 \mathrm{kcal} / \mathrm{g}$ dry wt (Studier, 1979). Very few organic molecules, e.g. formate, $1.3 \mathrm{kcal} / \mathrm{g}$; acetate, $3.5 \mathrm{kcal} / \mathrm{g}$; lactate, $3.6 \mathrm{kcal} / \mathrm{g}$; oxalate, $0.7 \mathrm{kcal} / \mathrm{g}$; urea, $2.5 \mathrm{kcal} / \mathrm{g}$; urate, $2.7 \mathrm{kcal} / \mathrm{g}$ have heats of combustion (Weast, 1975) in the range of cave cricket wastes.

Sample sizes preclude statistical analysis of calorific density of reproductive tracts; however, it certainly appears that dry and, especially, wet calorific density of female gonads is higher than the remaining carcass while male gonad calorific density is less than the remaining carcass (Table 1). Such probable differences result from marked differences in water content (Table 2) and probable higher lipid content in female gonads and lower lipid content in male gonads in comparison to the remaining carcass. The higher calorific density of gonad-free carcasses of large females in comparison to small and medium individuals of both sexes may reflect higher lipid content. It should be noted, however, that the carcass calorific contents of cave cricket carcasses (Table 1) are extremely low in comparison to carcass calorific density of most insects (Table 4 in Slansky and Scriber, 1984) indicating very low body lipid levels in cave crickets.

Data from the long-term weight-loss experiments (Fig. 2), along with information on water content (Table 3), allow the calculation of the rate of dry crop content utilized. When coupled to measured calorific densities (Table 1), an estimate of the rate of crop energy emptying is established. Since this rate represents the introduction of foodstuffs into the absorp- tive portion of the gut, it effectively represents or is comparable to the rate of ingestion of calorics by most species.

Rate of ingested dry mass, less rate of dry mass lost in wastes, yields assimilated dry mass and, through the use of calorific densities (Table 1), yields the rate of energy assimilation (Table 2). These values are used to calculate both the dry matter and calorific assimilation efficiencies for large crickets of both sexes (Table 3). Peters (1983) projects an average assimilation efficiency of about $69 \%$ for poikilotherms. Slansky and Scriber (1984) recently reviewed available information on food consumption and utilization in insects. Values for assimilation efficiencies reported in Table 2 of their review show levels which are generally much lower than reported here for cave crickets. Data are available only on larvae for most species in Slansky and Scriber's (1984) summary, so comparisons may not be valid. Woodring et al. (1979) give dry weight assimilation efficiencies for house crickets of $70-73 \%$, which closely matches the $71.9-73.9 \%$ found in cave crickets. The calorific assimilation efficiency in house crickets $(71-73 \%)$ is essentially identical for dry weight values, which is consistent with data for other insects (Slanksy and Scriber, 1984). In cave crickets, however, calorific assimilation efficiency (80.4$82.5 \%$ ) markedly exceeds dry weight levels due to the extreme drop in calorific density between crop contents and mixed wastes (Table 1).

Assimilated energy is partitioned within animals into energy used in secondary productivity (increase in fixed calories in gonads and carcasses) or "wasted" as respiration or metabolic rate. We have assumed a value of zero for secondary productivity over the observed time span and converted energy into metabolism (Table 2). Such an assumption yields an estimate of maximum metabolic rate. Expected metabolic rate for insects the size of $H$. subterraneus (Kayser and Heusner, 1964) is $1.93 \pm 0.05(N=12)$ $\mathrm{cal} / \mathrm{hr}$ based on CFLW, while the observed maximal metabolic rate for $H$. subterraneus is $1.08 \pm 0.12$ $(N=12) \mathrm{cal} / \mathrm{hr}$. The observed rate is $56.0 \%$ of the expected value and is significantly lower $(t=6.48$; d.f. $=22 ; P<0.001)$ than expected. Such a low metabolic rate seems to be characteristic of cavernicoles in comparison to related epigean species (Poulson and White, 1969; Culver, 1982).

An interesting relationship exists between $H$. subterraneus and Neaphaenops tellkampfii, as this troglobitic beetle derives the bulk of its energy input from 
ingestion of cave cricket eggs (Poulson, 1975; Norton et al., 1975; Kane and Poulson, 1976). Average dry weight of 11 apparently mature ova taken from the gonads of four female crickets was $3.10 \mathrm{mg} / \mathrm{egg}$ (range $=2.4-3.6 \mathrm{mg}$ ). Average wet weight $(5.2 \mathrm{mg}$ ) compares favorably with the value of $5.68 \mathrm{mg}$ reported by Kane and Poulson (1976) for laid eggs and nymphs of $H$. subterraneus. Our estimate of calorific density of eggs $(5.6 \mathrm{cal} / \mathrm{mg}$ in Table 2$)$ is somewhat less than the $7.5-8.0 \mathrm{cal} / \mathrm{mg}$ reported by the previous authors. Since $N$. tellkampfii weigh, about $7.0 \mathrm{mg}$ (Kane and Poulson, 1976), their estimated metabolic rate (Kayser and Heusner, 1964) is $3.72 \mathrm{cal} /$ day. Using the range of data reported above and assuming complete assimilation, consumption of one $\mathrm{H}$. subterraneus egg would support one $N$. tellkampfii for 5.1-7.3 days.

In terms of energy input into cave ecosystems in the form of digestive wastes, cave crickets average 2.82 dry $\mathrm{mg} /$ day for females ( $=6.59 \mathrm{cal} /$ day $)$ and $1.96 \mathrm{dry}$ $\mathrm{mg} /$ day for males $(=4.57 \mathrm{cal} / \mathrm{day}$ ) (from Tables 1 and 2). These absolute values are very much smaller than the egested energy for several bats, e.g. 470 and $370 \mathrm{cal} /$ day for Myotis thysanodes and $M$. lucifugus, respectively (O'Farrell et al., 1971), $630 \mathrm{cal} /$ day for Lasiurus cinereus (Brisbin, 1966) and $470 \mathrm{cal} /$ day for Lasionycteris noctivagans (Neuhauser and Brisbin, 1969). On a weight-specific basis, egested cricket energy ( 15.6 and $11.7 \mathrm{cal} / \mathrm{g}$ per day for females and males, respectively) are somewhat closer to, but still lower than, values for bats $(56.0$ and $46.9 \mathrm{cal} / \mathrm{g}$ per day for $M$. thysanodes and $M$. lucifugus, respectively; O'Farrell et al., 1971). This marked difference in energy input between cave crickets and bats correlates to the marked differences in cave ecosystem biomass supported by these trogloxenes. Additionally, since cave cricket wastes have been pretreated by crop microbes, potential energy in wastes is apparently highly refractory and unavailable as a carbon source to most troglobites (Lavoie, personal observation)

Acknowledgements - We would like to thank all of the many people who provided input and insights into this study. In particular, we would like to thank Tom Poulson and Mike Martin for reviewing drafts of the manuscript and making helpful suggestions. Ellen Levy provided insights into cricket biology and foraging. T. H. Hubbell identified the crickets and provided a monograph on their classification and biology. Terry Bellis and Ann Studier assisted with the field work. NPS personnel at Mammoth Cave National Park provided access to the caves. We would like to thank the Cave Research Foundation for use of their field facilities.

\section{REFERENCES}

Barr T. C. Jr (1967) Ecological studies in the Mammoth Cave system of Kentucky. I. The biota. Int. J. Speleol 3, 147-204.

Barr T. C. Jr (1968) Cave ecology and the evolution of troglobites. Evol. Biol. 2, 35-102.

Barr T. C. Jr and Kuehne R. A. (1971) Ecological studies in the Mammoth Cave system of Kentucky. II. The ecosystem. Ann. Speleol. 26, 47-96.
Brisbin I. L. Jr (1966) Energy utilization in a captive hoary bat. J. Mammal. 47, 719-720.

Campbell G. D. (1980) Aspects of the ecology, environmental physiology and behaviour of several Australian cave dwelling crickets. Ph.D. Dissertation, University of New South Wales.

Culver D. C. (1982) Cave Life: Evolution and Ecology. Harvard University Press, Cambridge, MA.

Harris J. A. (1973) Structure and dynamics of a cave population of the guano mite, Uroobovella coprophila (Womersley). Aust. J. Zool. 21, 239-275.

Hawes R. S. (1939) The flood factor in the ecology of caves. J. Anim. Ecol. 8, 1-5.

Hubbell T. H. and Norton R. M. (1978) The Systematics and Biology of the Cave-Crickets of the North American Tribe Hadenoecini (Orthoptera Saltatoria: Ensifera: Rhaphidophoridae: Dolichopodinae). Misc. Publ. Mus. Zool., Univ. Mich. No. 156.

Kane T. C., Norton R. M. and Poulson T. L. (1975) The ecology of a predaceous troglobitic beetle, Neaphaenops tellkampfii (Coleoptera: Carabidae, Trechinae). I. Seasonality of food input and early life history stages. Int. J. Speleol. 7, 45-54.

Kane T. C. and Poulson T. L. (1976) Foraging by cave beetles: spatial and temporal heterogeneity of prey. Ecology 57, 793-800.

Kayser C. and Heusner A. (1964) Etude comparative du metabolisme energetique dans la serie animale. J. Physiol. (Paris) 56, 489-524.

Lavoie K. H., Studier E. H., Apgar M. and Edwards J. (1986) Microorganisms associated with the crop of Hadenoecus subterraneus. Abstract of a presentation at the Nat. Speleol. Soc. Annual Meeting, Frankfort, KY. Bull. Nat. Speleol. Soc. (in press).

Leja W. and Poulson T. L. (1984) Nocturnal cave exodus and return: cave vs camel crickets. Cave Research Found. Ann. Report.

Levy E. S. (1976) Aspects of the biology of Hadenoecus subterraneus with special reference to foraging behavior. M.S. Thesis. Dept. Biol. Sci., University of Illinois-Chicago Circle, Chicago, Illinois.

Neuhauser H. N. and Brisbin I. L. Jr. (1969) Energy utilization in a captive silver haired bat. Bat Res. News 10, 30-31.

Norton R. M., Kane T. C. and Poulson T. L. (1975) The ecology of a predaceous troglobitic beetle, Neaphanops tellkampfi (Coleoptera: Carabidae: Trechinae). II. Adult seasonality, feeding and recruitment. Int. J. Speleol. 7, $55-64$.

O'Farrell M. J., Studier E. H. and Ewing W. G. (1971) Energy utilization and water requirements of captive Myotis thysanodes and Myotis lucifugus (Chiroptera). Comp. Biochem. Physiol. 39A, 547-552.

Peck S. B. (1976) The effect of cave temperatures on the distribution of cave-inhabiting terrestrial arthropods. Int. J. Speleol. 8, 309-321.

Peters R. H. (1983) The Ecological Implications of Body Size. Cambridge University Press, Cambridge.

Poulson T. L. (1975) Symposium on life histories of cave beetles: an introduction. Int. J. Speleol. 7, 1-5.

Poulson T. L. and Culver D. C. (1969) Diversity in terrestrial cave communities. Ecology 50, 153-158.

Poulson T. L. and Kane T. C. (1981) How food type determines community organization in caves. In Proceedings of the VII International Congress on Speleology (Edited by Beck B. F.), Vol. 1, pp. 56-59.

Poulson T. L. and White W. B. (1969) The cave environment. Science 165, 971-981.

Richards A. M. (1971) An ecological study of the cavernicolous fauna of the Nullarbor Plain, southern Australia. J. Zool., Lond. 164, 1-60.

Slansky F. Jr and Scriber J. M. (1984) Food consumption and utilization. In Comprehensive Insect Physiology, Bio- 
chemistry, and Pharmacology (Edited by Kerkut G. A. Weast R. C. (Ed.) (1975) Handbook of Chemistry and and Gilbert L. 1.), Vol. 4, Chapter 3, pp. 87-162. Per- Physics (1975-1976), 56th Edition, pp. D274-D279. CRC gamon Press, Oxford.

Studier E. H. (1979) Bioenergetics of growth, pregnancy and lactation in the laboratory mouse, Mus musculus. Comp. Biochem. Physiol. 64A, 473-481.

Press, Cleveland.

Woodring J. P., Clifford C. W. and Beckman B. R. (1979) Food utilization and metabolic efficiency in larval and adult house crickets. J. Insect Physiol. 25, 903-912. 